\title{
Perspectives
}

\section{Preparing for the Next Generation}

\author{
Presidential Address to the American Society for Clinical Investigation, Washington, DC, 7 May 1990
}

Stuart H. Orkin

Division of Hematology-Oncology, Children's Hospital, Department of Pediatrics, Harvard Medical School, Howard Hughes

Medical Institute, Boston, Massachusetts 02115

Members and guests, for the past year it has been my honor and pleasure to serve as President of the American Society of Clinical Investigation, an organization dedicated to the advancement of biomedical and clinical science. The health of our society and the vigor of these annual meetings reflect recent advances in the application of science to medicine and, more broadly, the overall state of academic medicine. We have a considerable tradition in this society. Many eminent physicians and investigators have preceeded me as President, and, I trust, many more will follow. As President of the ASCI, I have had the occasion to reflect on issues and problems related to the propagation of our species. And some of these concerns are the topic of my address this morning.

As those who know my academic history can attest, I am not the typical individual to have been chosen as President of the ASCI. In contrast to many recent Presidents, I have never served as Chairman of a Department of Medicine, as Chief of a Clinical Division, or as Branch Chief at the National Institutes of Health. I know little of the financial structure of American medicine, nor honestly have spent much time pondering its problems. In fact, as my clinical experience has been largely restricted to pediatrics, I know precious little about internal medicine, the primary focus of most of the members of the society. Instead, I have spent the vast majority of my academic career developing my personal research interests in the context and environment of a clinical division, working with clinical fellows and basic science postdoctoral fellows who come to my laboratory to pursue common research goals, and participating in the training of those who I expect will be my successors. So what then can this atypical ASCI president and pediatrician say to this group? My message is deceptively simple, yet a challenge to us all. If biomedical science and academic medicine are to remain vibrant and healthy into the next century, we must concern ourselves more than we have to date with the quality of, and commitment to, science education in our country, not just at the college and postgraduate levels but far earlier. At this moment the report card is not good, and future prospects depend on reversing this trend.

Biomedical science has experienced a profound revolution in the past decade, driven largely by advances in molecular biology. Recombinant DNA methods have become central not only to genetics per se, but to cell biology, cancer biology,

Received for publication 27 August 1990.

J. Clin. Invest.

(c) The American Society for Clinical Investigation, Inc.

0021-9738/90/12/1773/04 \$2.00

Volume 86, December 1990, 1773-1776 immunology, and neurobiology. Fundamental problems in all these areas have been solved or "cracked" in recent years. Many of the basic features of gene regulation and cell differentiation are now evident. Specific genes that participate in the initiation and progression of diverse malignancies are now known. The genetic and structural bases for antigen recognition and cell-cell interactions in the immune system are being defined. Furthermore, protein products generated through recombinant DNA technology are now making their way into the clinical arena as new pharmaceuticals. In fact, an industry still in its infancy, that of biotechnology, was born of this revolution.

Those of us pursuing research activities identified with clinical problems have been the beneficiaries of many basic discoveries and technical advances, often developed in what have traditionally been regarded as "basic science" or $\mathrm{Ph}$.D.based departments worldwide. Although there can be no accurate measure of the true impact of molecular biology on the course of clinical investigation, an impressive trend is evident from inspection of our plenary sessions over the past decade (Fig. 1). The percentage of delivered papers relating findings based on molecular cloning or the study of cloned genes and their expression is plotted for representative years during this period. Whereas such papers were infrequent in the years from 1980 to 1986 , they dominate thereafter. Such an abrupt transition necessitates the acquisition of a new vocabulary and new research skills. For many in the ASCI this has been an exhilarating challenge, met with great enthusiasm and success. For others, it has been a continuing frustration. As a major proponent and architect of this progression, though, I contend that the dye is cast. At present, molecular techniques are rapidly being assimilated in "nonmolecular laboratories", much the same as polyacrylamide gel electrophoresis and the routine use of antibodies were in the previous decade. The vast majority of you are very familiar with the jargon of molecular biology. Indeed, many of you have the most tangible evidence of these recent developments, a "PCR" machine, in your laboratories. What this revolution in technology announces loud and clear is that we must be prepared for change. We must be pliable enough to modify the course of our work with each new, and perhaps unanticipated, revolution in science. In 1986 Dr. Joseph Goldstein described a new clinical syndrome, "PAIDS" or paralyzed academic investigator's disease (1), which results from the inability to adapt in such a dynamic environment. The disease is still with us, and is usually fatal. The epidemic continues. My treatment is meant to prevent the first symptoms.

Many forces conspire to undermine the goals and aspirations of the ASCI and its members. Although biomedical research in this country is unparalleled elsewhere in the world, 


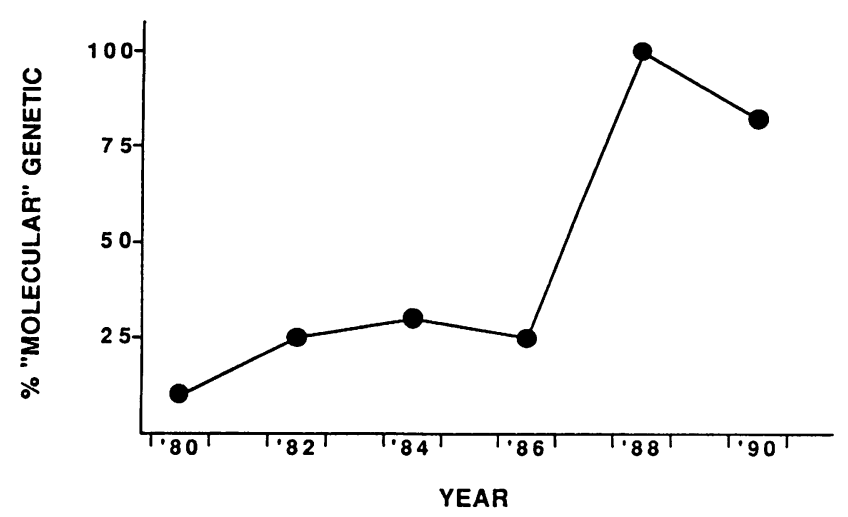

Figure 1. Rise of "molecular" papers presented at ASCI plenary sessions (1980-1990).

there is the sense that we are under assault. Some in our midsts feel that our "private" domain, human biology, is being wrested from us, as Ph.D.-trained molecular biologists, immunologists, or cell biologists have been drawn into the study of human systems to a greater extent over the past several years. As many fundamental mechanisms of gene regulation and differentiation are seen to be conserved from simple organisms to man, it is no longer considered an embarrassment for a "basic scientist" to investigate a human disorder. Although the public appears to have an insatiable appetite for "medical breakthroughs" reported weekly in the press, we also have the perception that biomedical research must be rather low on the priority list of our representatives in government. Even now, when old conflicts between East and West appear to be dissolving amid democratic and nationalistic fervor, we are told that the "peace dividend" for social concerns, and I infer also research, is likely to be small. At this time, consequent to these forces and compounded by administrative decisions, grant funding through the NIH is the most competitive and difficult in recent memory. If funding paylines are in the 10-15 percentile range, what message does this send to biomedical scientists, present or future? Although the immediate impass may be alleviated somewhat in the next few years, no one is so bold as to predict dramatic improvements soon enough. If all this were not discouraging, forces conspire to undermine medicine and medical research as a profession. Medical economics is now a major component of medical practice as well as academic medicine. Medicine, once idealized in the minds of the public, has lost much of its luster and is no longer viewed so highly by college students faced with the prospect of an expensive medical education and (perhaps) a tedious career thereafter. It is no wonder that a career in business, with the promise of a quicker (and more substantial) pay-off, is said to be more attractive. And, if this were not enough, the integrity of basic and clinical researchers has been impuned by those who fail to distinguish between interpretive differences encountered regularly in science and outright fraud. Instances of fraud, abuse, and conflict of interest in biomedical science are indeniable. Collectively, all engaged in our professional activities should be embarrassed. Nonetheless, these instances are rare and should not be used to fuel ambitions of those trying to regulate science or medicine. Inappropriate witch hunts directed at our nation's most respected and honorable scientists only serve to undermine the foundations of biomedical science.

So, times are difficult. Is it surprising that many department chairmen wonder whether the next generation of aca- demic researchers will emerge to take their places? While those in clinical circles are worrying about the influx of new talent, I can assure you that chairmen of basic science departments are concerned, too. Should we throw our hands up in despair and let our careers and the ASCI just fade away? I think not. The excitement and promise in the biomedical sciences are the greatest they have ever been. It is particularly ironic that at the moment at which both achievement and promise are the brighest, we dispair of current conditions and future prospects.

Numerous solutions have been proposed to address the perceived failure of current training mechanisms to attract sufficient numbers of talented individuals to pursue a career in biomedical research. A lengthy educational "pipeline" supplies future scientists and engineers (Fig. 2), proceeding from early stages of education through postgraduate training. With time there is progressive pruning, so that only a tiny fraction of entering high school students ultimately pursue careers in the sciences. Of approximately 4 million entering high school sophomores in 1977, slightly less than 10,000 (or just over 0.2\%) will earn Ph.D. degree in the sciences in 1992. Many stimuli to which students are exposed during their formative years may either increase or decrease the final percentage that choose a scientific path. Among educators, there is considerable debate regarding the consequences of intervention at each phase of the educational ladder. There are those who contend that maximal yield is attainable by capturing the minds of students at the earliest stages. Others contend that it is more cost effective to do so at the college level.

Preparation for a career in academic medical research in the 1990s and beyond requires a firm grounding and commitment to science that $I$ believe is not easily gained in the later years of formal education. In effect, the complexities of modern research in medicine require more extended training at the bench than previously the custom. Most of the programs currently in place to foster the development of biomedical scientists, in my view, focus dangerously late in the course of intellectual development. Examples of programs aimed at the graduate and postgraduate years include M.D.-Ph.D. programs,

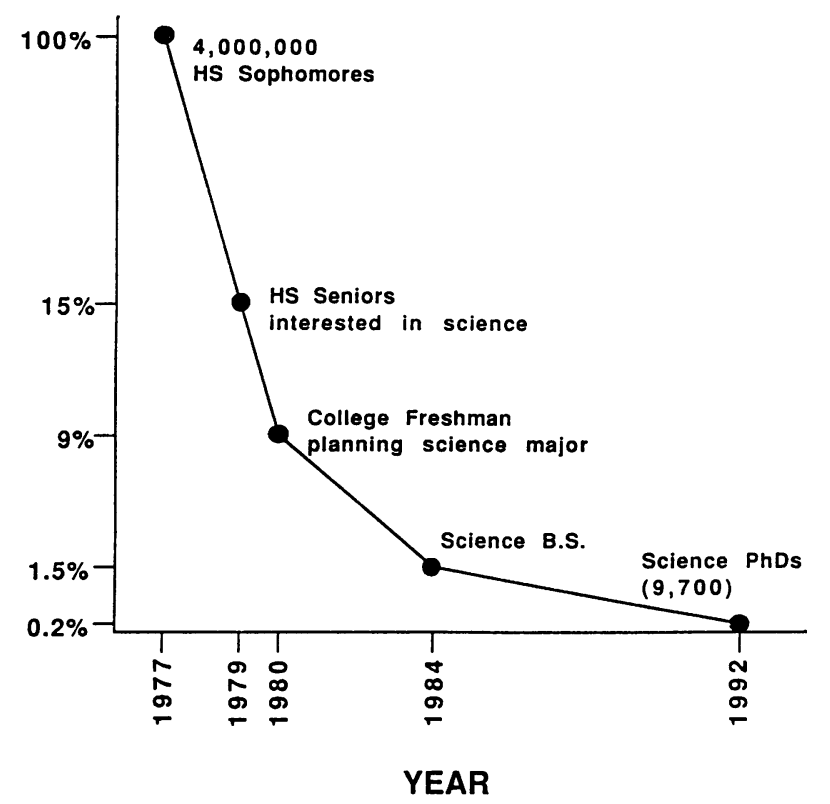

Figure 2. The science "pipeline". Adapted from reference 6. 
Physician Scientist and Clinical Investigator Awards. M.D.Ph.D. programs are best suited to draw the most talented college graduates into research, often in exchange for "no debt" medical education. Subspecialty training fellowships have traditionally been used as the major mechanism for developing medical academicians. Only more recently has the NIH Physician Scientist Award program been initiated to provide additional years in basic science training. Other agencies, notably the Howard Hughes Medical Institute, have also recognized the increasing need for such programs and have initiated mechanisms for graduate student and physician scientist support. Although these diverse programs for graduate and postgraduate education support are absolutely essential in the current environment, I am concerned that they are insufficient in the long-term for the enormous challenges ahead. Without doubt, our most talented fellows in specialty training match or exceed those who have come before both in potential and commitment. But, their numbers are inadequate to provide the investigators and teachers for the future. The veneer of academic biomedical science is all too thin.

The pediatrician within me keeps saying that the root of the problems we now face is much earlier than we have traditionally considered our concern. It is unreasonable to believe that a medical student or clinical fellow who has spent nearly 20 years in a formal education system that deemphasizes and misrepresents the sciences, should be lured into biomedical research through a relatively brief (three-to-five-year) training period in which both the tools of the trade are to be mastered and evidence of accomplishment is expected. Individuals at the fellowship stage of their careers face many, often conflicting, forces, including the need to learn a new language and discipline of research, the gymnastics required to manage longitudinal clinical responsibilities with the demands of the laboratory, and the urge to "get on with one's life", that is support and raise a family. Entering a new discipline, such as laboratory research, is never easy. When one tries to do so without a firm base, commitment, and love of scientific research, it is nearly impossible.

Numerous indicators make it abundantly clear that our educational systems in this country are failing at the task. For example, the UCLA Cooperative Institutional Research Program (CIRP) survey of entering college freshmen, a study begun in 1966 and continuing to the present, indicates that freshman interest in fundamental undergraduate science majors has dropped dramatically over the past 23 years, particularly in the physical sciences (2). Nonetheless, during a period that many of us view as the "golden" age of biological sciences, interest among freshmen in biology as a major has not kept pace. Freshman interest in faculty and research careers overall has waned over the past two decades (Fig. 3), so much so as to cause us to ask whether there will be a next generation of academicians. Substantial defection, or the switching from science to nonscience majors during the ensuing four years, renders projections from the freshman year overly optimistic. In parallel with these trends, the UCLA survey has documented an increasing interest in business careers, particularly among women (Fig. 4).

No solace can be gained by contemplating earlier education. Among high school students taking upper level biology, the United States ranked 14th among all countries surveyed for achievement, even though biology is the most popular high school science course (3). Whereas students in Singapore and Great Britain provided correct scores nearly two-thirds of the

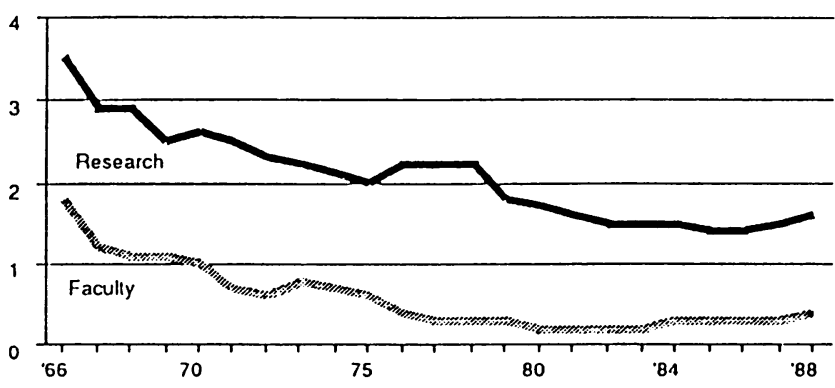

Figure 3. Freshman interest in faculty and research careers (percentages of first-time, full-time freshmen in all institutions). Reproduced from reference 2 .

time, US students were right only a little more than one-third. Statistical surveys of this kind can easily be distorted to support almost any position. However, no educators have come forward to praise the accomplishments of our students in the sciences. This is not something of which we should be proud.

The difficulties we face are rooted even earlier in our children's education. For one, we have the sense, perhaps as other generations have had before us, that our students and the populace overall are not as aware of "basic information" as we should be. Take, for example, the embarrassing failure of many students and their elders to know simple geography and current events. Educating students and the lay public about science has always posed a formidable problem. The heroic teacher of Tracy Kidder's best selling book Among Schoolchildren (4) laments that she feels inadequate in teaching science to her pupils. Her response is to avoid the subject.

She left science for last. For several other subjects she used textbooks, but only as outlines. She taught science right out of the book; this was one of those texts that takes pains with the obvious and gives the complex short shrift. Chris didn't know much science and didn't enjoy teaching it. . . . About one day in ten she canceled science altogether and announced-to cheers, Felippe's the loudest-an informal art lesson. She often felt guilty about science.

With such not-so-subtle cues it is no wonder that students create their own images of scientists long before they confront science or scientists in a meaningful way. In a classic study, Margaret Mead surveyed some 35,000 high school students in the mid-1950s regarding their views of scientists (5). A composite view of scientists is easily translated: scientists are nerds; but it was also expressed (fortunately) that science is important:

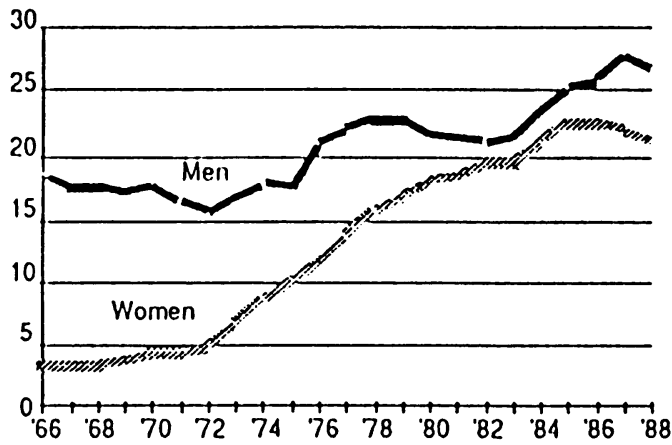

Figure 4. Rise in interest in business careers among women freshman (percentages, 1966-1988). Reproduced from reference 2. 
The scientist is a man who wears a white coat and works in a laboratory. He is elderly or middle aged and wears glasses . . . He may be bald. He may wear a beard, may be unshaven and unkempt. He may be stooped and tired . . . He is surrounded by equipment: test tubes, bunsen burners, flasks and bottles, a jungle gym of blown glass tubes and weird machines with dials . . . He spends his days doing experiments. . . He experiments with plants and animals, cutting them apart, injecting serum into animals . . .

Scientists were viewed as eccentric:

The scientist is a brain . . . He spends his days indoors. . . . His work is uninteresting, dull, monotonous, tedious, time consuming . . . He may live in a cold water flat . . . He may be dangerous. . . . If he does medical research, he may bring home disease, or may use himself as a guinea pig, or may even accidentally kill someone. . . . He is so involved with his work that he doesn't know what is going on in the world . . . He has no other interests and neglects his body for his mind . . . He has no social life, no other intellectual interests, no hobbies, or relaxations. He bores his wife. . . . He brings home work and also bugs and creepy things. He may force his children to become scientists also.

A scientist should not marry. No one wants to be such a scientist or to marry him.

We must take particular note of where scientists might live, perhaps a hint to those providing our funding. Traditionally science has also been viewed as obscure, as reflected in this drawing by a high school student (Fig. 5).

With this as background must we wonder why it is that the public has little knowledge or understanding of science? Is it remarkable that legislators believe that science and medicine are important, but cannot muster the votes to give our funding a higher priority score? Why does a mediocre baseball player earn 10-20 times more than our most committed and productive biomedical scientists? Although lobbying our representatives to redress grievances may lessen difficulties in the short run, only progressive improvement in science education from

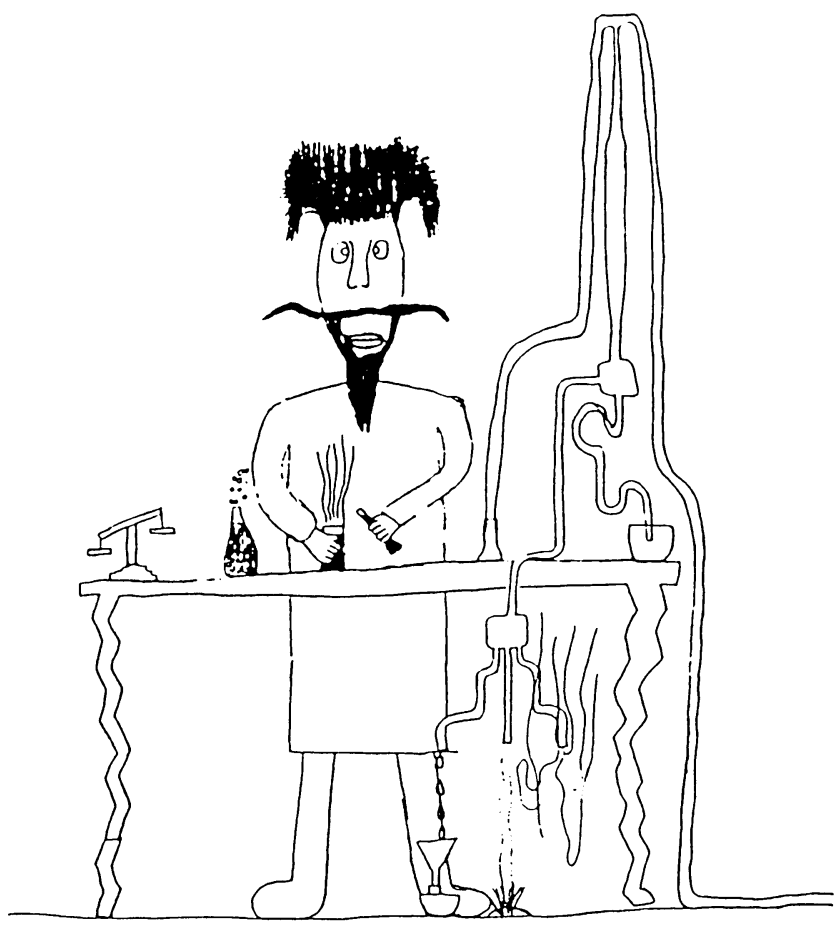

Figure 5. A high school student's view of a scientist. Reproduced from reference 6 . the bottom up will succeed in reorienting priorities in the future.

Educators have discussed and debated how best to educate students and others about science, and thereby turn the tide. One common theme is that we must stimulate curiosity and excitement with direct participation. Almost all agree that rather than emphasizing dry facts and new vocabulary, teachers must strive to open students' eyes to the wonder of science and to the excitment of learning and discovery through active participation in simple experiments, tailored appropriately for age. In effect, as academic investigators we attempt to do much the same, but at a much later time in intellectual development. Although deficiencies in science education have been apparent for some time, their potential consequences to medicine, science, and to our country are now being addressed openly. Hopeful signs are appearing. For example, several private foundations, including the Albert P. Sloan Foundation and the Howard Hughes Medical Institute, have supported programs for the improvement of science education at the secondary school and college level. Science education in liberal arts and traditionally "nonscience" institutions has been a primary focus of new initiatives. National news magazines in recent weeks have discussed the general problem and highlighted several extraordinary teachers whose courses have captured the imagination of their students. We should hope that these extraordinary teachers become the ordinary.

Recognition of the national consequences of scientific illiteracy has awakened our political leaders. Last February President Bush and the nation's governors announced a national education goal "that by the year 2000, US students will be first in the world in mathematics and science achievement." There are few among us who believe we will meet this goal on our current course. Nonetheless, recognition of the need for improved science education, at the highest level of this country, should give us some small comfort. I do not have the background nor the experience in public policy and general education to present a coherent program for the solutions to this challenge. What I have come to realize of late, though, is that our efforts in academic medicine and research are inextricably linked to these issues of science education. The future of academic biomedical research does not rest in our hands alone, but in those of elementary, high school, and college instructors whom we shall never meet. If the "pipeline" is to be replenished, it must be done so at the source. Thank you.

\section{References}

1. Goldstein, J. D. 1986. On the origin and prevention of PAIDS (Paralyzed Academic Investigator's Disease Syndrome. J. Clin. Invest. 78:848-854.

2. Green K. C. 1989. A profile of undergraduates in the sciences. In Sigma Xi Conference on Undergraduate Education in Science, Mathematics, and Engineering at the Wingspread Conference Center, Racine, WI (23 January 1989).

3. 1990. Science education: finery and fads or fundamental change? J. NIH Res. 2:25-26.

4. Kidder, T. 1989. Among Schoolchildren. Houghton Mifflin Co., Boston, MA.

5. Mead, M., and R. Metraux. 1957. Image of the scientist among high-school students: a pilot study. Science (Wash. DC). 126:384-390.

6. 1988. Educating Scientists and Engineers: Grade School to Grad School. Office of Technology Assessment, Congress of the United States, Washington, DC. 